\title{
Esmolol versus ketamine-remifentanil combination for early postoperative analgesia after laparoscopic cholecystectomy: a randomized controlled trial \\ L'esmolol versus l'association kétamine-rémifentanil pour une analgésie postopératoire précoce après cholécystectomie par laparoscopie: une étude randomisée contrôlée
}

\author{
Servando López-Álvarez, MD • Monica Mayo-Moldes, MD • \\ Matilde Zaballos, MD, PhD • Belen García Iglesias, MD • \\ Rafael Blanco-Dávila, MD \\ Received: 29 January 2011 / Accepted: 15 February 2012/Published online: 2 March 2012 \\ (C) Canadian Anesthesiologists' Society 2012
}

\begin{abstract}
Purpose Controversy surrounds the optimal technique to moderate pain after laparoscopic cholecystectomy (LC). Opioid analgesics, sympatholytic drugs, and adjuvants, such as ketamine, have all been used. We compared esmolol with a combination of remifentanil plus ketamine in patients undergoing $L C$ to determine the impact of these drugs on morphine requirements and pain control.

Methods Sixty American Society of Anesthesiologists physical status I-II patients undergoing LC and anesthetized with sevoflurane were randomized to one of two groups. Group E patients received a bolus of esmolol $0.5 \mathrm{mg} \cdot \mathrm{kg}^{-1} \mathrm{iv}$ at induction followed by an infusion of $5-15 \mu \mathrm{g} \cdot \mathrm{kg}^{-1} \cdot \mathrm{min}^{-1}$, and Group $R-K$ patients received a bolus of ketamine
\end{abstract}

S. López-Álvarez, MD · B. G. Iglesias, MD

Department of Anesthesiology, Hospital Abente y Lago,

Complexo Hospitalario Universitario, A Coruña, Spain

M. Mayo-Moldes, MD

Department of Anesthesiology, Hospital Meixoiro, Complexo

Hospitalario Universitario de Vigo, Vigo, Spain

M. Zaballos, MD, PhD ( $\square)$

Department of Anesthesiology, Servicio de Anestesia (Planta

Baja), Hospital Universitario Gregorio Marañón, Doctor

Esquerdo, 46, 28007 Madrid, Spain

e-mail: mati@plagaro.net

M. Zaballos, MD, PhD

Professor of Toxicology, Complutense University, Complutense

University, Madrid, Spain

R. Blanco-Dávila, MD

Department of Anesthesiology, Lewisham Hospital, London, UK
$0.5 \mathrm{mg} \cdot \mathrm{kg}^{-1}$ iv and remifentanil $0.5 \mu \mathrm{g} \cdot \mathrm{kg}^{-1}$ iv at induction followed by a remifentanil infusion titrated over a range of 0.1-0.5 $\mu \mathrm{g} \cdot \mathrm{kg}^{-1} \cdot \mathrm{min}^{-1}$. All patients received paracetamol, dexketoprofen, and levobupivacaine via infiltration of laparoscopic port sites. After surgery, a predetermined bolus of morphine was administered according to a verbal numerical rating scale (VNRS) for pain intensity. The primary outcome of interest was postoperative morphine requirement.

Results Median consumption of morphine was higher in Group $R$ - $K$ than in Group E (5 mg [4-6] vs $0 \mathrm{mg}$ [0-2], respectively; $P<0.001)$. In the postanesthesia care unit, patients in Group $R-K$ had higher pain scores than patients in Group $E$ (difference in maximum VNRS, -11; 95\% confidence interval (CI), -19 to -3). The concentration of sevoflurane to maintain a bispectral index $\sim 40$ was higher in Group E than in Group R-K (between-group difference $0.3 \%$; $95 \%$ CI, 0.15 to 0.40). The incidence of postoperative nausea and vomiting was similar between the two groups.

Conclusion Intraoperative esmolol infusion reduces morphine requirements and provides more effective analgesia compared with a combination of remifentanil-ketamine given by infusion in patients undergoing $L C$.

\section{Résumé}

Objectif La technique optimale à utiliser pour diminuer la douleur après une cholécystectomie par laparoscopie (CL) fait encore l'objet de controverses. Les antalgiques morphiniques, les sympatholytiques et adjuvants, comme la kétamine, ont tous été utilisés. Nous avons comparé l'esmolol à une association de rémifentanil-kétamine chez 
des patients subissant une CL pour déterminer l'impact de ces médicaments sur les besoins en morphine et le contrôle de la douleur.

Méthodes Soixante patients ayant un statut physique I-II selon les critères de l'American Society of Anesthesiologists et subissant une CL ont été anesthésiés avec du sevoflurane et randomisés en deux groupes. Les patients du Groupe E ont reçu un bolus d'esmolol $\left(0,5 \mathrm{mg} \cdot \mathrm{kg}^{-1} \mathrm{IV}\right)$ à l'induction, suivi d'une perfusion de 5 à $15 \mu \mathrm{g} \cdot \mathrm{kg}^{-1} \cdot \mathrm{min}^{-1}$, tandis que les patients $d u$ groupe $R-K$ ont reçu un bolus de kétamine $\left(0,5 \mathrm{mg} \cdot \mathrm{kg}^{-1} \mathrm{IV}\right)$ et de rémifentanil $\left(0,5 \mu \mathrm{g} \cdot \mathrm{kg}^{-1} \mathrm{IV}\right)$ à l'induction, suivis par une perfusion de rémifentanil ajustée dans une plage de 0,1 à $0,5 \mu \mathrm{g} \cdot \mathrm{kg}^{-1} \cdot \mathrm{min}^{-1}$. Tous les patients ont reçu du paracétamol, du dexketoprofen et des infiltrations de lévobupivacaïne au niveau des sites d'accès de laparoscopie. Après l'intervention chirurgicale, un bolus prédéfini de morphine était administré en fonction d'une échelle d'évaluation numérique verbale de l'intensité de la douleur (VNRS). Le critère d'évaluation principal d'intérêt était le besoin postopératoire en morphine.

Résultats La consommation médiane de morphine a été plus importante dans le groupe $R-K$ que dans le groupe $E$ (respectivement: $5 \mathrm{mg}$ [4-6] contre $0 \mathrm{mg}$ [0-2]; $P<0,001)$. En salle de réveil, les patients $d u$ groupe $R-K$ ont présenté des scores de douleur supérieurs aux patients du groupe E (différence de VNRS maximum: -11; intervalle de confiance à $95 \%$ [IC]: -19 à-3). La concentration de sévoflurane pour maintenir un indice bispectral proche de 40 a été supérieure dans le groupe E par rapport au groupe $R-K$ (différence intergroupe: 0,3\%; IC à $95 \%: 0,15$ à 0,40). L'incidence des nausées et vomissements postopératoires a été comparable entre les deux groupes.

Conclusion Une perfusion peropératoire d'esmolol diminue les besoins en morphine et procure une analgésie efficace par rapport à une association de rémifentanil-kétamine administrée en perfusion chez des patients subissant une CL.

Although the intensity of postoperative pain following laparoscopic cholecystectomy (LC) is reduced compared with traditional open cholecytectomy, LC still requires a multimodal analgesic approach since it is associated with complex incisional, visceral, and referred pain. ${ }^{1,2}$ However, multimodal analgesic strategies that consist of opioids, local anesthetics applied to the incision, and nonsteroidal anti-inflammatory drugs do not entirely eliminate postoperative pain., ${ }^{2,3}$

For LC, it has been recommended that short-acting opioids, such as remifentanil, be used to moderate the sympathetic-adrenergic surgical stress response. ${ }^{4}$ However, remifentanil can induce hyperalgesia and, consequently, severe postoperative pain due to its rapid metabolism and the effect of its abrupt withdrawal on regulation of the second messenger. This hyperalgesia can be modulated by activation of N-methyl-D-aspartic acid (NMDA) receptors; hence, administration of antagonists, such as ketamine, has proven beneficial in controlling remifentanil-induced hyperalgesia. $^{5,6}$ Alternatively, beta-adrenergic blocking drugs have been shown to reduce postoperative opioid requirements, suggesting an antinociceptive effect of these agents. $^{7-10}$

A previous study in patients undergoing LC showed that esmolol, and not remifentanil, was associated with reduced postoperative fentanyl requirements. However, the amount of influence that the hyperalgesic effect (attributed to remifentanil) contributed to the results in this study remains unknown. ${ }^{11}$

This is a novel study evaluating the postoperative analgesic efficacy of esmolol compared with remifentanil combined with ketamine following LC. We hypothesized that the administration of esmolol during LC would be associated with lower morphine requirements in the immediate postoperative period than the administration of remifentanil combined with low-dose ketamine.

\section{Methods}

Inclusion criteria included patients who were American Society of Anesthesiologists (ASA) physical status I or II, ages $18-85 \mathrm{yr}$, and a body mass index $18-35 \mathrm{~kg} \cdot \mathrm{m}^{-2}$. Exclusion criteria included patients with liver disease, kidney failure, heart disease, diabetes, chronic treatment with opioids or beta-blockers, asthma or bronchial hyperactivity, allergy to any of the study drugs, airway disease, and risk of aspiration.

Investigators, S.L. and M.M., recruited patients at Abente and Lago Hospital, A Coruña and at Meixoiro Complexo Hospitalario Universitario, Vigo from January 15 to June 30, 2007. The local and ethics committees at both hospitals approved the study protocol, and all patients provided written informed consent. An investigator who was not participating in the trial prepared the randomization sequence using the Research-Randomizer ${ }^{\circledR}$ program, version 3.0; http://www.randomizer.org/). Allocation was concealed by storing the randomization sequence in consecutively numbered opaque sealed envelopes. Immediately prior to induction, the attending anesthesiologist opened the next envelope in the sequence to reveal the treatment allocation. This anesthesiologist was not involved in any aspect of postoperative data collection or analysis. A trained nurse, blinded to treatment allocation and with no access to the intraoperative records, performed all outcome assessments in the postanesthesia care unit (PACU). Patients remained blinded to their treatment allocation throughout the study. 
Anesthetic technique

After premedication with intravenous midazolam $\left(0.3 \mathrm{mg} \cdot \mathrm{kg}^{-1}\right)$, standard monitoring was applied consisting of electrocardiography, noninvasive blood pressure, oxygen saturation $\left(\mathrm{O}_{2}\right.$ sat $)$, end-tidal $\mathrm{CO}_{2}\left(\mathrm{EtCO}_{2}\right)$, inspired-end-tidal sevoflurane concentrations, and anesthetic depth as assessed by bispectral index (BIS) (Monitor BIS Module A-2000 Revision 3.12, Aspects Medical Systems, Inc., Norwood, MA, USA). Patients in the esmolol group (Group E) received esmolol $0.5 \mathrm{mg} \cdot \mathrm{kg}^{-1} i v$ at induction followed by a continuous infusion of esmolol $5-15 \mu \mathrm{g} \cdot \mathrm{kg}^{-1} \cdot \mathrm{min}^{-1}$. Patients in the remifentanil-ketamine group (Group $\mathrm{R}-\mathrm{K}$ ) received ketamine $0.5 \mathrm{mg} \cdot \mathrm{kg}^{-1} i v$ and remifentanil $0.5 \mu \mathrm{g} \cdot \mathrm{kg}^{-1} i v$ at induction followed by an infusion of remifentanil 0.1$0.50 \mu \mathrm{g} \cdot \mathrm{kg}^{-1} \cdot \mathrm{min}^{-1}$. Anesthesia was induced with propofol $2.5 \mathrm{mg} \cdot \mathrm{kg}^{-1} i v$ and a single dose of rocuronium $0.8 \mathrm{mg} \cdot \mathrm{kg}^{-1}$ $i v$. A size 4 LMA Supreme ${ }^{\mathrm{TM}}$ was inserted for females and a size 5 LMA Supreme was inserted for males. The cuff of the LMA Supreme was inflated to $60 \mathrm{~cm} \mathrm{H}_{2} \mathrm{O}$, the functioning of the drain tube was checked with an orogastric tube, and the sealing pressure was ascertained using the method described by Keller et al. ${ }^{12}$ The patients' lungs were ventilated using pressure-controlled ventilation at a fresh gas flow of 4 $\mathrm{L} \cdot \mathrm{min}^{-1}$ (50\% mixture of oxygen-air). The pressure and the ventilatory frequency were adjusted to obtain an expired tidal volume of $8 \mathrm{~mL} \cdot \mathrm{kg}^{-1}$ at an $\mathrm{EtCO}_{2}$ of $35-40 \mathrm{mmHg}$.

Anesthesia was maintained with sevoflurane 1-1.5 MAC targeted to a BIS value of $\sim 40$. Paracetamol $1 \mathrm{~g} i v$ and dexamethasone $8 \mathrm{mg} i v$ were administered after induction, and dexketoprofen $50 \mathrm{mg}$ and ondansetron $4 \mathrm{mg}$ were administered intravenously $30 \mathrm{~min}$ before the end of surgery. The port insertions were infiltrated with $0.5 \%$ levobupivacaine at the end of the procedure. Esmolol and remifentanil infusions were adjusted to maintain a mean arterial blood pressure and heart rate within $20 \%$ of baseline values. Hypotension (mean arterial blood pressure $<55 \mathrm{mmHg}$ ) and bradycardia (heart rate $<45$ beats $\bullet \mathrm{min}^{-1}$ ) longer than one minute in duration were treated with ephedrine $10 \mathrm{mg} i v$ boluses or atropine $0.1 \mathrm{mg} \cdot \mathrm{kg}^{-1} \mathrm{iv}$, respectively. At the end of surgery, the LMA Supreme was removed when the patient responded to simple commands.

Measurements and statistical plan

All patients remained in the PACU until study completion. Pain intensity was recorded according to a verbal numerical rating scale (VNRS) $(0=$ absence of pain, and $100=$ unbearable pain) at ten, 30, 60, 120, and $180 \mathrm{~min}$ post PACU admission. Morphine $2 \mathrm{mg} i v$ was administered for postoperative analgesia whenever the patient had a VNRS $>50$, with boluses repeated every five minutes, as required to maintain the $\mathrm{VNRS}<50$. The primary outcome of interest was the cumulative total consumption of morphine in the PACU.

The following data were recorded: heart rate, blood pressure, oxygen saturation, BIS, average end-tidal sevoflurane (pre- and post-insertion of the LMA Supreme [1.5, five, and ten minutes], pre- and post-pneumoperitoneum [five and ten minutes], pre- and five minutes post-withdrawal of the LMA Supreme), and rate of esmolol or remifentanil infusions. The cumulative doses of esmolol and remifentanil were recorded.

Finally, the frequencies of postoperative nausea and vomiting (PONV) were recorded based on a numerical scale of 0 to 3 ( $0=$ absent; $1=$ feeling nauseous; $2=$ vomiting that required treatment; $3=$ vomiting that persisted despite treatment). Vomiting was treated with metoclopramide $10 \mathrm{mg} i v$. Sedation levels were assessed using the Ramsay scale. Patients were also asked to record their overall level of satisfaction with treatment on a fourpoint scale of 1 to $4(1=\mathrm{a}$ bad experience to $4=$ an excellent experience).

Quantitative variables are expressed as mean, if normally distributed, and as median [interquartile range] if not, and qualitative variables are expressed as frequency and percentages. Quantitative variables were compared using an independent Student's $t$ test or the Mann-Whitney U test. The Chi square test or Fisher's exact test were applied for the qualitative variables. The statistical analysis was conducted using SPSS ${ }^{\circledR} 11.0$ (SPSS Inc. Chicago, IL, USA). All reported $P$ values are two sided.

The primary outcome was the amount of morphine used for postoperative analgesia in the PACU. Secondary outcome measures were the proportion of patients requiring morphine, the intensity of pain (VNRS) and the maximal overall VNRS (max-VNRS) pain score during the study period, ${ }^{13}$ the incidence of PONV, and the sedation level (Ramsay scale).

The sample size requirement was based on preliminary data from a previous pilot study with ten patients in which morphine requirements were $4 \mathrm{mg}$ in Group $\mathrm{R}-\mathrm{K}$ and $2.7 \mathrm{mg}$ in Group E (variance, 2.19). Thus, 30 patients in each group would detect a $30 \%$ reduction in morphine requirements in the early recovery period with alpha risk of $5 \%$ a statistical power of $90 \%$.

\section{Results}

Sixty-five patients were assessed for eligibility. Five of these patients did not meet the criteria for inclusion (three patients were classified as ASA III, one patient was drug dependent, and one patient was being treated with beta blockers. The final sample comprised 60 patients, 30 in Group E and 30 in Group R-K. The groups were 
Table 1 Demographic, surgical, and anesthetic features

\begin{tabular}{lll}
\hline & $\begin{array}{l}\text { Esmolol } \\
n=30\end{array}$ & $\begin{array}{l}\text { Remifentanil- } \\
\text { Ketamine } \\
n=30\end{array}$ \\
\hline $\begin{array}{l}\text { Age, } \mathrm{yr} \\
\text { Female/male }\end{array}$ & $55(16) 56$ & $56(12) 55$ \\
BMI, $\mathrm{kg} \cdot \mathrm{m}^{2}$ & $17 / 13$ & $20 / 10$ \\
ASA I/II & $27.4(4.27) 27$ & $29.18(4.69) 29$ \\
Smoker n (\%) & $17 / 13$ & $6 / 24$ \\
History of PONV $n(\%)$ & $9(30)$ & $10(33)$ \\
$\begin{array}{l}\text { Intraoperative data } \\
\text { Duration of surgery, min }\end{array}$ & $1(3)$ & $0(0)$ \\
$\begin{array}{l}\text { Duration of anesthesia, min } \\
\text { Total esmolol, mg.kg }{ }^{-1}\end{array}$ & $64(15) 62$ & $70(17) 75$ \\
$\begin{array}{l}\text { Total remifentanil, } \mu \mathrm{g} \cdot \mathrm{kg} \\
\text { Number of patients needed }\end{array}$ & $5.2(3.4)$ & - \\
$\quad-$ & $21(7)$ \\
atropine & & 1 \\
Number of patients needed & 3 & 9 \\
$\quad$ ephedrine & & 0 \\
Number of patients needed & 0 & \\
$\quad$ laparotomy & & \\
\hline
\end{tabular}

Quantitative variables are displayed as mean (standard deviation) median, and the qualitative variables as frequency and percentages. $\mathrm{BMI}=$ body mass index; ASA $=$ American Society of Anesthesiologists physical status; $\mathrm{PONV}=$ postoperative nausea and vomiting

homogeneous with respect to demographic variables, physical status, comorbidities, duration of surgery and anesthesia, and intraoperative adverse hemodynamic events (Table 1).

\section{Morphine consumption and postoperative pain}

Median consumption of morphine was $5 \mathrm{mg}$ [4-6] in Group $\mathrm{R}-\mathrm{K}$ vs $0 \mathrm{mg}[0-2]$ in Group $\mathrm{E}(P<0.001)$ (Fig. 1). Twenty-five of $30(83 \%)$ patients in Group R-K and seven of $30(23 \%)$ patients in Group E required morphine (difference $=60 \%$; $95 \%$ confidence interval (CI), 36 to 75 ). The patients in Group R-K presented with higher pain scores in the PACU than patients in Group E (Fig. 2) (difference in maximum VNRS, -11 ; 95\% CI, -19 to -3 ).

\section{Secondary outcomes}

The concentration of sevoflurane needed to maintain BIS 40 was significantly higher in the Group $E$ than in Group R-K (difference, $0.3 \%$; $95 \%$ CI, 0.15 to 0.40 ). None of the patients reported recall of intraoperative events. Intraoperative hemodynamic variables were similar in both groups throughout surgery, and they were maintained within $20 \%$ of the respective baseline values. Occasional episodes of bradycardia and hypotension requiring atropine

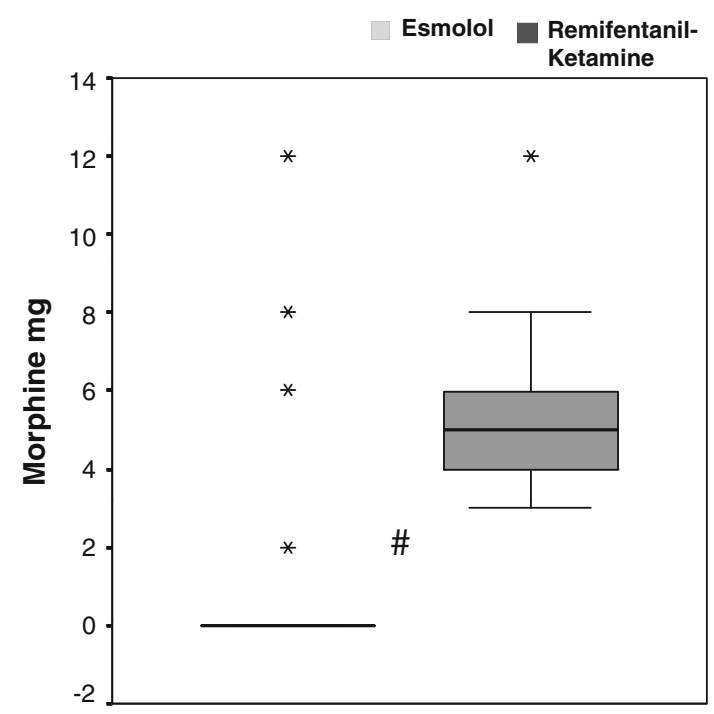

Fig. 1 Cumulative morphine consumption. Data are presented as median, interquartile range, range, and extreme values. $\# P<0.001$ is a significant difference

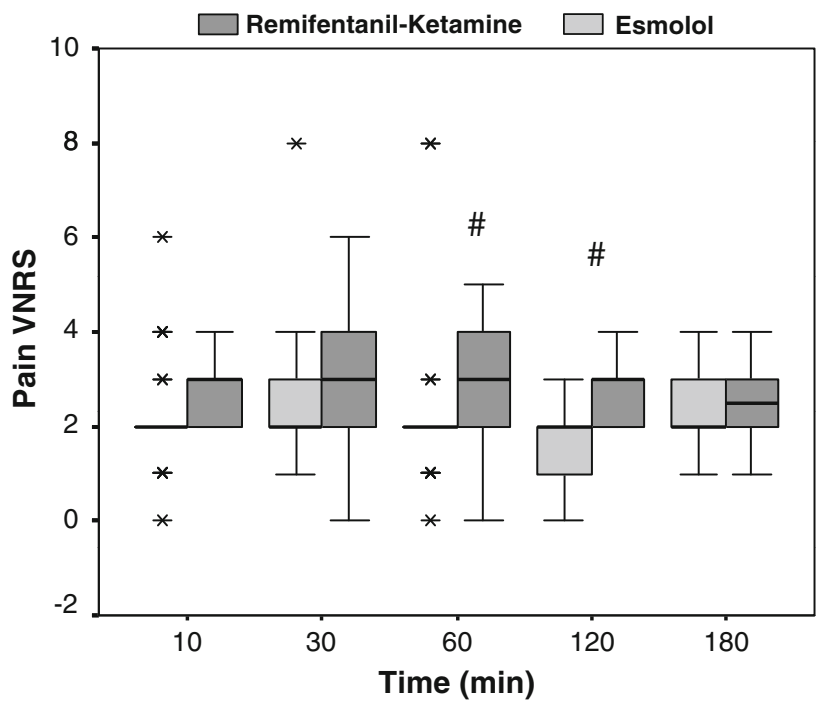

Fig. 2 Verbal numerical rating scale for pain intensity in the postanesthesia care unit. Data are presented as median, interquartile range, range, and extreme values. $\# P=0.01$ is a significant difference

or ephedrine were observed with a low but similar frequency in both groups (Table 1).

The incidence of PONV was 26\% in Group R-K vs 20\% in Group E. A similar number of patients received metoclopramide in both groups. Five of the seven patients in Group E who received morphine had PONV vs six of the 25 patients who received morphine in the Group R-K. Three patients had persistent vomiting despite treatment (one patient from the Group E and two patients from Group $\mathrm{R}-\mathrm{K})$. The mean levels of sedation in the PACU were 
Table 2 Level of sedation of patients during their stay in the PACU, as determined by the Ramsay scale. Only three of the six levels of the Ramsay scale are shown as no patient's sedation surpassed level 3

\begin{tabular}{|c|c|c|c|c|c|c|c|c|c|c|}
\hline \multirow[t]{2}{*}{ Sedation level } & \multicolumn{2}{|l|}{$10 \min$} & \multicolumn{2}{|l|}{$30 \mathrm{~min}$} & \multicolumn{2}{|l|}{$60 \min$} & \multicolumn{2}{|l|}{$120 \mathrm{~min}$} & \multicolumn{2}{|l|}{$180 \mathrm{~min}$} \\
\hline & Group E & Group R-K & Group E & Group R-K & Group E & Group R-K & Group E & Group R-K & Group E & Group R-K \\
\hline 1 & 0 & 1 & 0 & 4 & 0 & 3 & 0 & 2 & 0 & 0 \\
\hline 2 & 25 & 21 & 29 & 26 & 30 & 27 & 30 & 28 & 30 & 30 \\
\hline 3 & 5 & 8 & 1 & 0 & 0 & 0 & 0 & 0 & 0 & 0 \\
\hline
\end{tabular}

Values are number of patients. PACU $=$ postanesthesia care unit

similar in both groups within $30 \mathrm{~min}$ after surgery (Table 2). Overall levels of patient satisfaction were similar in the two groups.

\section{Discussion}

In this study, a continuous intraoperative infusion of esmolol $\left(5-15 \mu \mathrm{g} \cdot \mathrm{kg}^{-1} \cdot \mathrm{min}^{-1}\right)$ was found to reduce the postoperative morphine requirement after LC compared with a remifentanil-ketamine infusion. Although the difference in median morphine consumption between the two groups was relatively small $(5 \mathrm{mg})$, the proportion of patients requiring opioid treatment (those with moderatesevere pain, VNRS pain score of 5) was considerably larger in Group R-K (83\%) compared with Group E (23\%). We did not observe any between-group differences in opioid adverse effects, such as PONV and sedation.

Pain management in laparoscopic surgery remains a challenge in clinical practice, and studies continue to report severe pain after surgery. ${ }^{2,4,14}$ All patients in this study received multimodal analgesia, which many previous studies have shown to facilitate early recovery. This study shows that the administration of esmolol is more effective in reducing postoperative narcotic requirements than remifentanil-ketamine when both are administered with multimodal analgesia during LC.

The mechanism underlying these non-cardiovascular effects of beta blockers is controversial. Some studies show synergism with the hypnotic effect, while others disregard this action. ${ }^{9,15-19}$ The antinociceptive effect of esmolol is also controversial, although experimental and clinical observations point to an analgesic effect associated with the involvement of the sympathetic nervous system in nociception. $^{9-11,20,21}$ This effect, however, is not universally confirmed. $^{22}$

In a study of 100 patients undergoing laparoscopic hysterectomy, Chia et al. ${ }^{9}$ compared the use of esmolol with a control group of patients who received saline. These authors noticed a decrease in intraoperative requirements for fentanyl and reduced consumption of morphine during the first three days after surgery, with an average consumption of $37.3 \mathrm{mg}$ and $54.7 \mathrm{mg}$ in the esmolol and control groups, respectively. They proposed that attenuation of the intraoperative nociceptive stimulation of esmolol reduced the consequences of adrenergic dysregulation.

White et al. ${ }^{10}$ used three distinct protocols to compare analgesic requirements in patients undergoing gynecologic laparoscopy: a group managed with esmolol alone, a group managed with nicardipine combined with esmolol, and a control group managed with saline. Their results showed that $80 \%$ of patients in the control group required postoperative analgesia compared with $47 \%$ of patients in the esmolol group and $40 \%$ of patients in the esmolol-nicardipine group.

Collard et al. ${ }^{11}$ did not administer opioids in the esmolol group, thus making it possible to evaluate the supposed antinociceptive effect of esmolol. This study, which used a protocol similar to ours, showed that the esmolol group required less fentanyl in the postoperative period than the other two groups. A noticeable difference between their results and ours is that $90 \%$ of their patients (all three groups) required analgesia compared with $53 \%$ of the total of our sample and only $23 \%$ of the esmolol group. There are important differences between the study of Collard et al. and ours. In Collard et al.'s study, desflurane was adjusted to a BIS score of $\sim 60$, while we administered sevoflurane to maintain a BIS score of $\sim 40$. Similarly, Collard et al. used lower doses of esmolol and remifentanil in their study than we used in ours $\left(1.3 \mathrm{mg} \cdot \mathrm{kg}^{-1} \mathrm{vs}\right.$ $5.2 \mathrm{mg} \cdot \mathrm{kg}^{-1}$ and $7.6 \mu \mathrm{g} \cdot \mathrm{kg}^{-1}$ vs $21 \mu \mathrm{g} \cdot \mathrm{kg}^{-1}$, respectively). We adjusted esmolol and remifentanil doses to keep both blood pressure and heart rate limits at around $20 \%$ of respective baseline values, while Collard et al. modified the infusion rates of both drugs based on heart rate alone to maintain its limit within $20 \%$ of baseline. A possible reason for reduced postoperative requirement in our study could be due to both the antinociceptive effects of the esmolol administered at a higher dose and the possible analgesic effect described for sevoflurane. ${ }^{23}$ Both studies also differed in the multimodal strategy applied. Collard et al. administered paracetamol rectally rather than intravenously, a route with higher bioavailability. In addition, the laparoscopy ports were infiltrated with lidocaine, whereas we used levobupivacaine to confer a longer duration of the effect of the local anesthetic. 
Another important difference between our study and Collard et al.'s study ${ }^{11}$ is their use of remifentanil as the sole analgesic without adding ketamine. Human and animal studies have shown that remifentanil is associated with hyperalgesia. One of the mechanisms involved is activation of the NMDA receptors, which is thought to be modulated by ketamine. ${ }^{24,25}$ The overall lower requirement for analgesia (morphine) in our patients compared with the requirement (fentanyl) in their study $(53 \%$ vs $90 \%$, respectively) could have been due in part to the use of ketamine, which decreased the hyperalgesic effects of remifentanil-although this combination was less effective for pain control than esmolol. However, the design of our study does not allow us to infer an analgesic effect which is exclusively attributable to esmolol because we did not include a control group, and in addition, all patients received a multimodal regimen with paracetamol, dexketoprofen, and infiltration of the laparoscopy insertion ports with levobupivacaine. The overall incidence of PONV in our study (23\%) was lower than that reported by Collard et al. ${ }^{11}(51 \%)$, even though double antiemetic prophylaxis was administered to patients in both studies. This observation could be related in part to the different percentages of female subjects $(70 \%$ in their study $v s 61 \%$ in our study). ${ }^{26}$

Our study has several limitations. Anesthesiologists were not blinded to the study drug administered, although they were not involved in evaluating postoperative pain scores or sedation levels, and so they could not influence the morphine requirements. Also, sevoflurane was titrated to maintain a BIS value of $\sim 40$, which necessitated a higher sevoflurane concentration in Group E.

In conclusion, this study shows that intraoperative infusion of esmolol $\left(5-15 \mu \mathrm{g} \cdot \mathrm{kg}^{-1} \cdot \mathrm{min}^{-1}\right)$ in patients undergoing laparoscopic cholecystectomy reduces opioid requirements and improves postoperative analgesia. During inhaled anesthesia with sevoflurane, this non-opioid pharmacologic strategy provides an effective alternative for pain management in the early postoperative period following laparoscopic cholecystectomy.

Conflicts of interest None declared.

\section{References}

1. Gurusamy K, Junnarkar S, Farouk M, Davidson BR. Metaanalysis of randomized controlled trials on the safety and effectiveness of day-case laparoscopic cholecystectomy. Br J Surg 2008; 95: 161-8.

2. Bisgaart T. Analgesic treatment after laparoscopic cholecystectomy: a critical assessment of the evidence. Anesthesiology 2006; 104: 835-46.
3. Bisgaard T, Klarskov B, Kehlet H, Rosenberg J. Preoperative dexamethasone improves surgical outcome after laparoscopic cholecystectomy: a randomized double-blind placebo-controlled trial. Ann Surg 2003; 238: 651-60.

4. Kehlet H, Gray AW, Bonnet F, et al. A procedure-specific systematic review and consensus recommendations for postoperative analgesia following laparoscopic cholecystectomy. Surg Endosc 2005; 19: 1396-415.

5. Servin FS, Billard V. Remifentanil and other opioids. Handb Exp Pharmacol 2008; 182: 283-311.

6. Joly V, Richebe P, Guignard B, et al. Remifentanil-induced postoperative hyperalgesia and its prevention with small-dose ketamine. Anesthesiology 2005; 103: 147-55.

7. Zaugg M, Tagliente T, Lucchinetti E, et al. Beneficial effects from beta-adrenergic blockade in elderly patients undergoing noncardiac surgery. Anesthesiology 1999; 91: 1674-86.

8. Johansen JW, Flaishon R, Sebel PS. Esmolol reduces anesthetic requirement for skin incision during propofol/nitrous oxide/ morphine anesthesia. Anesthesiology 1997; 86: 364-71.

9. Chia YY, Chan MH, Ko NH, Liu K. Role of beta-blockade in anaesthesia and postoperative pain management after hysterectomy. Br J Anaesth 2004; 93: 799-805.

10. White PF, Wang B, Tang $J$, Wender RH, Naruse R, Sloninsky A. Effect of intraoperative use of esmolol and nicardipine on recovery after ambulatory surgery. Anesth Analg 2003; 97: 1633-8.

11. Collard V, Mistraletti G, Taqi A, et al. Intraoperative esmolol infusion in the absence of opioids spares postoperative fentanyl in patients undergoing ambulatory laparoscopic cholecystectomy. Anesth Analg 2007; 105: 1255-62.

12. Keller C, Brimacombe JR, Keller K, Morris R. Comparison of four methods for assessing airway sealing pressure with the laryngeal mask airway in adult patients. Br J Anaesth 1999; 82: 286-7.

13. Smith I, Walley G, Bridgman S. Omitting fentanyl reduces nausea and vomiting, without increasing pain, after sevoflurane for day surgery. Eur J Anaesthesiol 2008; 25: 790-9.

14. Bisgaard T, Klarskov B, Rosenberg J, Kehlet H. Characteristics and prediction of early pain after laparoscopic cholecystectomy. Pain 2001; 90: 261-9.

15. Johansen JW, Schneider G, Windsor AM, Sebel PS. Esmolol potentiates reduction of minimum alveolar isoflurane concentration by alfentanil. Anesth Analg 1998; 87: 671-6.

16. Yang H, Fayad A. Are $\beta$-blockers anesthestics? Can J Anesth 2003; 50: 627-30.

17. Kadoi Y, Saito S. Possible indications of beta-blockers in the perioperative period other than prevention of cardiac ischemia. J Anesth 2010; 24: 81-95.

18. Oda $Y$, Nishikawa K, Hase I, Asada A. The short-acting beta1adrenoceptor antagonists esmolol and landiolol suppress the bispectral index response to tracheal intubation during sevoflurane anesthesia. Anesth Analg 2005; 100: 733-7.

19. Smith I, Van Hemelrijck J, White PF. Efficacy of esmolol versus alfentanil as a supplement to propofol-nitrous oxide anesthesia. Anesth Analg 1991; 73: 540-6.

20. Davidson EM, Doursout MF, Szmuk P, Chelly JE. Antinociceptive and cardiovascular properties of esmolol following formalin injection in rats. Can J Anesth 2001; 48: 59-64.

21. Zhao H, Sugawara T, Miura S, Iijima T, Kashimoto S. Intrathecal landiolol inhibits nociception and spinal c-Fos expression in the mouse formalin test. Can J Anesth 2007; 54: 201-7.

22. Coloma M, Chiu JW, White PF, Armbruster SC. The use of esmolol as an alternative to remifentanil during desflurane anesthesia for fast track outpatient gynecologic laparoscopic surgery. Anesth Analg 2001; 92: 352-7.

23. Matute E, Rivera-Arconada I, Lopez-García JA. Effects of propofol and sevoflurane on the excitability of rat spinal 
motoneurones and nociceptive reflexes in vitro. $\mathrm{Br} \mathrm{J}$ Anaesth 2004; 93: 422-7.

24. Angst MS, Clark JD. Opioid-induced hyperalgesia: a qualitative systematic review. Anesthesiology 2006; 104: 570-87.

25. Koppert W, Sittl R, Scheuber K, Alsheimer M, Schmelz M, Schuttler J. Differential modulation of remifentanil-induced analgesia and postinfusion hyperalgesia by S-ketamine and clonidine in humans. Anesthesiology 2003; 99: 152-9.

26. Apfel CC, Laara E, Koivuranta M, Greim CA, Roewer N. A simplified risk score for predicting postoperative nausea and vomiting: conclusions from cross-validations between two centers. Anesthesiology 1999; 91: 693-700. 